\title{
Desenvolvimento profissional docente: um estudo de caso com professores do Projeto Musicalização Infantil de Blumenau/SC
}

\author{
GIAN MARCO DE OLIVEIRA \\ REGINA FINCK SCHAMBECK
}

\begin{abstract}
Licenciado em Música e Especialista em Educação Musical pela Universidade Regional de Blumenau (FURB), Mestre em Música pelo Programa de Pós-Graduação em Música (PPGMUS) da Universidade do Estado de Santa Catarina (UDESC) na Área de Educação Musical na condição de Bolsista CAPES, membro do Grupo de Pesquisa Música e Educação (MusE) e professor no Projeto Musicalização Infantil de Blumenau/SC.

AFILIAÇÃO: Universidade do Estado de Santa Catarina (UDESC)

Licenciada em Educação Artística-Habilitação em Música pela Universidade do Estado de Santa Catarina, com mestrado e doutorado pelo Programa de Pós-Graduação em Educação da Universidade Federal do Rio Grande do Sul (UFRGS). Professora Associada da Universidade do Estado de Santa Catarina (UDESC), atua no Departamento de Música e no Programa de Pós-Graduação em Música - PPGMUS e do Programa de Pós-Graduação Mestrado Profissional em Artes (PROFARTES). Desenvolve pesquisas na área de formação de professores, inclusão de alunos com deficiências e a repercussão das políticas públicas de educação especial.

Universidade do Estado de Santa Catarina (UDESC)
\end{abstract}




\section{- RESUMO}

Este trabalho é um recorte de pesquisa de mestrado realizada no Programa de PósGraduação em Música (PPGMUS) da Universidade do Estado de Santa Catarina (UDESC) na área de Educação Musical. O Projeto Musicalização Infantil (PMI), contexto deste trabalho, atende crianças da Educação Infantil da Rede Municipal de Ensino de Blumenau/SC. No segundo semestre de 2017 o projeto contou com uma equipe de dezoito professores de música, formada por graduandos a mestres. A pesquisa teve como objetivo geral identificar processos de desenvolvimento profissional docente no PMI a partir das perspectivas de seus professores. O referencial teórico apoia-se nas perspectivas de investigação de desenvolvimento profissional docente de Mizukami (2010, 2013), Hookey (2002), Conway e Edgar (2014). Considera-se que nas interações entre professores do PMI há um reconhecer-se na categoria profissional e um apoio mútuo com vistas à aprendizagem e novas conquistas. Nas interações com professores de turma, professores do PMI aprendem sobre a criança, o que colabora para desenvolverem seu conhecimento sobre o ensino - a musicalização infantil.

\section{PALAVRAS-CHAVE}

Educação musical, desenvolvimento profissional docente, professores de música, educação infantil.

\section{- ABSTRACT}

This paper is an excerpt from a dissertation held in the Music Graduate Program at the Universidade do Estado de Santa Catarina in the Music Education area. The Projeto Musicalização Infantil (PMI), context of this research, attends children of the municipal Early Childhood Education of Blumenau/SC. PMI was formed by a team of eighteen music teachers from undergraduates to masters on the second half of 2017. This research aimed to identify processes of professional development in the PMI by the perspectives of its teachers. The theoretical framework is based on perspectives about investigation of professional development of Mizukami $(2010,2013)$, Hookey (2002), Conway and Edgar (2014). Findings reveal an auto-recognition in the professional category and a mutual cover by interactions between music teachers in searching for learning and new achievements. PMI teachers learn about the child in interactions with general classroom teachers. This collaborates to develop their knowledge about music teaching.

\section{KEYWORDS}

Music Education, teacher professional development, music teachers, early childhood education. 


\section{Introdução}

O Projeto Musicalização Infantil (PMI) é integrado ao currículo da Educação Básica, Educação Infantil, de Blumenau/SC, completando em julho de 2018 treze anos de história. Atende por ano aproximadamente 12 mil crianças de 0 a 5 anos de idade em 78 Centros de Educação Infantil (CEls). Para o segundo semestre de 2017, contou com um grupo de 18 professores cuja titulação abrange profissionais graduandos a mestres.

No PMI são realizadas reuniões de trabalho mensais com os professores. Nesses encontros eles discutem sobre demandas pedagógicas, atendimento às crianças, planejamento do projeto e socializam práticas profissionais. A reunião de trabalho abre espaço para os professores se organizarem enquanto grupo e partiIharem vivências profissionais. Além das reuniões, há outros meios em que professores de música do PMI possam interagir entre si: meio eletrônico [e-mails, mensagens], professores iniciantes que acompanham a atuação de professores mais experientes e suporte oferecido pela coordenação do PMI. Mizukami (2013) ressalta que reuniões e encontros entre professores podem favorecer, entre outros, a troca de experiências, a comparação de resultados entre práticas pedagógicas e o apoio entre profissionais através de uma abordagem construtivo-colaborativa (COLE; KNOWLES, 1993 apud MIZUKAMI, 2013, p.41).

Além do mais, os professores do PMI atuam nas turmas de educação infantil em parceria com os professores de turma. Tal situação oportuniza interações entre esses profissionais. Diante de um cenário que favorece o aprendizado entre professores de música na Educação Infantil, buscou-se valorizar os processos de desenvolvimento profissional docente, os aspectos individuais, coletivos, contextuais e organizacionais orientados em direção à mudança na base de conhecimento e nas ações dos professores do PMI e a construção de conhecimento sobre a matéria, o ensino e os alunos como um resultado de relação dialética entre o individual e o coletivo (HOOKEY, 2002; MIZUKAMI, 2013).

A pesquisa ${ }^{1}$ teve como objetivo geral identificar processos de desenvolvimento profissional docente no PMI a partir das perspectivas de seus professores. Neste artigo, procurou-se contemplar as colaborações entre profissionais e as partiIhas de vivências de professores do PMI, considerando suas vozes no que diz respeito aos desafios e necessidades relacionadas ao desenvolvimento profissional docente.

\section{Revisão de Literatura}

O desenvolvimento profissional de professores de música em serviço na Educação Básica é problematizado por alguns estudos. De maneira geral, os dados mais utilizados para a realização desses estudos são os relatos dos próprios professores a respeito de questões levantadas pelos pesquisadores sobre a temática. Pereira (2016) investigou as trajetórias de trabalho de professores licenciados em música nas Escolas Municipais de Educação Infantil da Rede Municipal de Ensino de Porto Alegre. A autora considera que professores de música reconstroem suas

\footnotetext{
${ }_{1}$ A pesquisa contou com apoio da Coordenação de Aperfeiçoamento de Pessoal de Nível Superior - Brasil (CAPES) - Código de Financiamento 001.
}

ouvirouver Uberlândia v. 14 n. 2 p. 452-465 jul.|dez. 2018 
experiências anteriores através da interação e convivência com crianças e com outros profissionais que trabalham na educação infantil, e, conforme se apropriam do contexto, vão modificando sua forma de pensar, em direção a tornarem-se, além de professores de música, professores de crianças (PEREIRA, 2016, p. 63-65).

Gaulke (2013) realizou um estudo com o objetivo de compreender como o professor iniciante lida com as dimensões dos fenômenos educativo-musicais escolares (p. 92). Entre outras evidências, a autora destaca que ter clareza dos seus princípios, observar e conversar com os colegas, recorrer a leituras e materiais didáticos são estratégias usadas pelos professores de música iniciantes para lidar com uma realidade totalmente nova e para ampliar seu repertório docente (p. 97). Por meio da metáfora de uma roda de bicicleta e seu movimento em uma superfície, que representa toda a movimentação que ocorre na aprendizagem da docência de música na escola de educação básica, Gaulke (2013) explica seu entendimento da construção da aprendizagem da docência de música. A autora considera que "a aprendizagem da docência é o movimento do professor em busca do aprender, da superação dos desafios; esse movimento é o que o faz manter o equilíbrio, assim como acontece ao andarmos de bicicleta" (p. 102).

Em estudo posterior, Gaulke (2017) procurou compreender como ocorre o processo de desenvolvimento profissional do professor de música a partir da sua relação com a escola de educação básica. A autora propõe uma simbologia do barco no mar como uma forma de ilustrar o entendimento da autoformação. O barco é o desenvolvimento profissional, o professor com sua vontade e energia guia o barco, a realidade escolar o lugar - também construído pelas experiências ali vividas, e o navegar nesse lugar promove o encontro de pessoas - as conchas, deixando marcas nesse barco. Para ela, o lugar constitui os eixos que sustentam o desenvolvimento profissional: o outro, o eu e a construção do eu com o outro. Há também a toca - a morada, porto seguro - não fixo - onde o professor constrói lugar em si mesmo. A autora considera que se reconhecer na experiência na e com a escola é "condição do desenvolvimento profissional do professor de música, sendo a experiência com o lugar o que constitui a toca". (GAULKE, 2017 p. 6).

\section{Referencial Teórico}

O referencial teórico apoia-se nas perspectivas de investigação de desenvolvimento profissional docente de Mizukami (2010, 2013), Hookey (2002), Conway e Edgar (2014). Considerando o ensino como uma profissão numa sociedade democrática em constante transformação, Mizukami (2013) indica a necessidade de os processos formativos enfatizarem três eixos essenciais à constituição de uma base de conhecimento para a docência, que são compreendidos por suas inter-relações. São eles: conhecimento dos alunos, seus processos de desenvolvimento e seus contextos socioculturais; conhecimento da matéria e dos objetivos curriculares; conhecimento do ensino.

Hookey (2002) realizou uma revisão acerca da pesquisa norte-americana sobre desenvolvimento profissional de professores de música em serviço. A autora destaca o que pesquisadores puderam dizer sobre o assunto, a natureza das problemáticas que eles enfrentaram ou revelaram, e questões que eles deixaram para 
outros responderem (p. 887). De acordo com a autora:

O termo desenvolvimento profissional tem múltiplos significados. Destes, quatro têm um impacto em como nós delineamos e interpretamos pesquisa: desenvolvimento profissional como

- um processo de mudança pessoal profissional,

- um conjunto de atividades delineado para promover mudança pessoal profissional,

- um projeto de vida, e,

- uma estrutura abrangente para mudança profissional.

Num nível fundamental, desenvolvimento profissional refere-se à mudança na base de conhecimento e nas ações dos professores. (HOOKEY, 2002, p. 888).

Para Mizukami et al. (2010), entende-se base de conhecimento como "o conjunto de compreensões, conhecimentos, habilidades e disposições necessário para atuação efetiva em situações específicas de ensino e aprendizagem" (p. 67). Se desenvolvimento profissional refere-se à mudança na base de conhecimento e nas ações dos professores, é possível questionar que fatores geram mudanças, e, por conseguinte, o desenvolvimento profissional.

Conway e Edgar (2014) realizaram um trabalho similar ao de Hookey (2002), mas doze anos depois. Os autores organizaram a produção acadêmica norte-americana sobre a temática a partir das seguintes categorias:

Desenvolvimento Profissional de Professores de Música Iniciantes: Desafios Enfrentados por Professores de Música; Suporte para Professores de Música por meio de Mentoria e Indução;

Desenvolvimento Profissional de Professores de Música Experientes: Comunidades de Prática; Fazer Musical como Desenvolvimento Profissional; Pós-Graduação como Desenvolvimento Profissional; Pesquisa Ação / Pesquisa Professor como Desenvolvimento Profissional;

Perspectiva / Ciclo de Carreira (CONWAY; EDGAR, 2014, p. 4-18).

As questões tratadas por meio dos autores apresentados na Revisão de Literatura e Referencial Teórico orientaram a codificação e a elaboração de categorias da pesquisa, bem como deram suporte para as análises a seguir apresentadas.

\section{Metodologia e contexto de pesquisa}

A pesquisa realizada teve abordagem qualitativa (SANDÍN ESTEBAN, 2010) e como método o estudo de caso (YIN, 2009). Foram utilizados como técnicas e instrumentos de produção de dados observações não participantes das reuniões de trabalho do PMI, dois grupos focais com professores do projeto e proposição de questionário para perfil profissional desses professores.

$\mathrm{Na}$ intenção de atender aos critérios éticos de pesquisa, o projeto (CAAE 7073717.1.0000.0118) foi submetido ao Comitê de Ética e Pesquisa da Universidade do Estado de Santa Catarina, visando preservar a integridade de todos os envolvidos na pesquisa, e aprovado em 28/04/2017 mediante parecer de número 
2.038.411.

Como procedimento de análise, foi realizada a codificação dos dados produzidos com base no referencial teórico anteriormente apresentado. Foi utilizado como ferramenta de codificação e categorização de dados o software N-VIVO 11. A codificação teve como fontes as transcrições dos dois grupos focais realizados com os professores do PMI. O software foi disponibilizado pelo Grupo de Pesquisa Música e Educação (MusE), o qual dispõe de licença paga.

No segundo semestre de 2017, período em que foi realizado o primeiro grupo focal, o PMI contava com 18 professores e professoras de música, sendo que uma delas é também coordenadora do projeto. Referente ao período acima determinado, 16 professores(as) aceitaram participar da pesquisa. Um preferiu não participar e outro não compareceu às reuniões de trabalho. Entre os(as) que aceitaram participar da pesquisa, 11 são professoras (69\%) e 5 são professores (31\%). Por motivos diversos, as professoras Emília e Gabriele (pseudônimos) não participaram do questionário para perfil profissional. Para Profa. Glória foi oportunizado o questionário por meio eletrônico. Os(as) demais professores(as) responderam ao questionário presencialmente em reunião de trabalho no dia 30/11/2017. A seguir, um panorama sobre a formação acadêmica dos professores.

O primeiro grupo focal foi realizado em 26/10/2017 e contou com a participação de nove professoras e quatro professores. O segundo grupo focal foi realizado em 19/04/2018 com a participação de três professoras e três professores.

\begin{tabular}{|c|c|c|c|c|c|c|c|}
\hline Pseud. & Idade & Licenciatura & Ano & Especialização & Ano & Mestrado & Ano \\
\hline Bárbara & 29 & Artes - Música & 2010 & Educação Musical & 2016 & Especial 1 & 2017 \\
\hline Bia & 54 & Artes - Música & 2011 & Educação Musical & 2016 & & \\
\hline \multicolumn{8}{|l|}{ Emilia* } \\
\hline Felicia & 32 & Artes - Música & 2011 & Educação Musical & 2012 & & \\
\hline Flávia & 33 & Artes - Música & 2006 & Ludopedagogia & 2008 & & \\
\hline II & & & & Educação Musical & 2011 & & \\
\hline \multicolumn{8}{|l|}{ Gabriele* } \\
\hline Glória & 29 & Música & 2011 & Educação Musical & 2012 & Educação & $\begin{array}{l}\text { Cur- } \\
\text { sando }\end{array}$ \\
\hline Gustavo & 24 & Música & 2016 & & & & \\
\hline Jorge & 37 & Música & 2014 & Educação Musical & 2016 & Especial 2 & 2016 \\
\hline Maitê & 60 & Música & 2013 & & & & \\
\hline Mateus & 26 & Música & 2015 & & & & \\
\hline Milena & 49 & Artes Visuais & 2015 & & & & \\
\hline II & & Música & Cursando & & & & \\
\hline Murilo & 42 & Artes - Música & 2001 & & & & \\
\hline Priscila & 29 & Artes - Música & 2011 & Educação Musical & 2012 & & \\
\hline Rafaela & 49 & Música & 2016 & Arte e E ducação & Cursando & & \\
\hline Teodoro & 26 & Música & 2012 & & & $\begin{array}{l}\text { Musicologia } \\
\text { / Etnomus. }\end{array}$ & 2014 \\
\hline \multicolumn{8}{|c|}{$\begin{array}{l}\text { * Participaram da pesquisa, m as não do questionário para perfil profissional. } \\
1 \text { Aluna especial do Mestrado em Música - Área: Educação Musical, na disciplina Educação Musical Coral. } \\
2 \text { Aluno especial do Mestrado em Música - Área: Educação Musical, na disciplina Tópicos Especiais em } \\
\text { Educação Musical II. }\end{array}$} \\
\hline
\end{tabular}

Figura 1- Formação acadêmica dos Professores. Fonte: Questionário Perfil Profissional (30/11/2017). Elaborado pelos autores. 
A seguir, na seção de análise de dados, os números de incidência que acompanham entre parênteses os assuntos relatados representam o número de vezes que a afirmação ou o assunto foi mencionado durante os dois grupos focais. Um assunto, uma reivindicação ou uma afirmação podem ser levantados mais de uma vez por um mesmo professor. Portanto, os números de incidência dizem respeito à recorrência do assunto e não ao número de professores que estão afirmando algo.

\section{Processos de aprendizagem profissional docente dos professores do PMI}

Hookey (2002), Mizukami $(2010,2013)$ e Conway e Edgar (2014) tratam do desenvolvimento profissional por meio da prática profissional, de colaborações entre professores, de organizações e da pós-graduação. Segundo Hookey (2002) "num nível fundamental, desenvolvimento profissional refere-se à mudança na base de conhecimento e nas ações dos professores" (HOOKEY, 2002, p. 888). Ao serem provocados sobre que fatores geram mudança na base de conhecimento e nas suas ações, inicialmente professores do PMI afirmam que aprender é um ato voluntário (2) e que maturidade profissional pode ser um desses fatores (4).

Profa. Priscila - Eu acho que, maturidade [seja um dos quadradinhos que promovem mudança]. [...] Porque no início é realmente difícil. Você é inexperiente, você não tem domínio das crianças. Então é complicado. [...] a maturidade, eu acho que, caberia num desses quadradinhos. Porque você só vai conseguir se desafiar, sair da zona de conforto, promover a mudança na tua base nas tuas ações a partir do momento que tu confias em ti, que tu tens maturidade para isso. Porque enquanto tu és inexperiente, o desastre pode ser... [Profa. Flávia: pode ser grande] gigante (Grupo Focal 02, 19/04/2018).

Cabe refletir sobre a autoconfiança mencionada por Profa. Priscila. Quais caminhos são possíveis para que o professor de música se insira, e continue, na Educação Infantil confiando em si mesmo o suficiente para impulsionar as mudanças necessárias para sua atuação profissional? A formação inicial e atuação profissional ao longo da carreira vão oportunizando aprendizagens e recursos para os professores atenderem, de alguma forma, às demandas da sala de aula. Entretanto, pode haver - e geralmente há - dissonâncias entre a bagagem de recursos que o professor acumulou ao longo de sua trajetória profissional e as demandas postas a ele em sala de aula, dado que a escola é um ambiente em constante transformação. Gaulke (2017) afirma que ao assumirem os seus jeitos, suas crenças e acreditarem em si como professores que ensinam e aprendem, os professores conseguiriam deixar algumas práticas de lado, esculpindo-se como professores conforme o lugar em que estão. Para a autora "a segurança que nasce do tempo de prática na escola também permite a alguns professores "desdizerem" teóricos e construírem conhecimentos próprios” (GAULKE, 2017, p. 203).

No que diz respeito às condições relacionadas ao aprender a ensinar de novas formas, professores necessitam de oportunidades para experimentar o ensino e observar tais experiências, "precisam ser novamente aprendizes, não mera- 
mente de pedagogia aplicada, mas de ideias, debates e formas de conhecimentos que caracterizam diferentes áreas do conhecimento e temas que permeiam tais áreas" (MCDIARMID, 1995 apud MIZUKAMI et al., 2010, p. 79-80).

Na perspectiva da aprendizagem na prática profissional o "aprender fazendo" é um meio recorrente nos relatos dos professores do PMI para a promoção do desenvolvimento profissional. Para Gaulke (2017) "foi a escola que fez dos professores ensinantes e aprendizes, e foi a prática na sala de aula que pôde mostrar caminhos para que pudessem aprender e, assim, conseguissem se vincular a esse espaço" (GAULKE, 2017, p. 197). Professores do PMI afirmam aprender com planejamentos que não dão certo (2), na realização de atividades com as crianças (3), por meio de vivências profissionais diversas (3) e na reflexão sobre a prática (7):

Prof. Jorge - [...] diariamente mesmo, não é hipocrisia, não, eu me pego a todo momento percebendo que certas coisas que eu faço ainda não estão bem acertadas. [Já] Outras coisas, opa que legal isso. Não via isso sobre esse aspecto. [...] A gente começa a prestar cada vez mais atenção no embasamento das práticas que a gente faz (Grupo Focal 01, 26/10/2017).

Neste sentido, ao valorizar as "práticas que a gente faz" estão em acordo com os pressupostos apontados por Gaulke (2013) que afirma que para ocorrer a aprendizagem profissional necessita-se de um tempo, um tempo de conquistas, tentativas, erros e acertos, e de o professor de música reconhecer-se na pluralidade da categoria docente sem deixar de ter sua singularidade. Inclusive, a autora ressalta que a construção da docência, em sua gênese, ocorre por meio de um retorno e da reflexão do professor de música aprendente sobre si e sobre sua prática (GAULKE, 2013, p. 100).

Conforme supracitado, Prof. Jorge afirma que a reflexão sobre a prática profissional contribui para encontrar novas e melhores possibilidades de atuação. Em relação à reflexão e ao embasamento sobre a prática, McDiarmid (1995) afirma que os professores necessitam:

\footnotetext{
Empreender avaliação crítica de suas práticas para aprender a ensinar de novas maneiras, implicando a delimitação de tempo e de oportunidade para saírem física e mentalmente de seu trabalho diário de sala de aula, de forma a poderem questionar, ler, discutir, obter informações, observar, pensar, escrever e experimentar (MCDIARMID, 1995 apud MIZUKAMl et al, 2010, p. 79-80).
}

Os professores da Educação Básica do PMI têm previsto $1 / 4$ do total de sua carga horária para o tempo de hora-atividade, conforme Decreto № 9645/2012 (BLUMENAU, 2012). Por exemplo, um professor com carga horária de 40 horas-relógio semanais possui, dessas, 8 horas-atividade. Tal condição trabalhista municipal difere da proposta pelo governo federal, conforme PARECER CNE/CEB №: 18/2012 de 2/10/2012 (BRASIL, 2012), o qual determina destinar no máximo 2/3 da jornada para interação com estudantes e no mínimo $1 / 3$ da jornada para atividades extra- 
classe (BRASIL, 2012, p. 19). Com $1 / 3$ da carga horária de trabalho destinada à hora atividade, professores do PMI teriam melhores condições para atender aos projetos macro dos CEls, atuar conjuntamente com os demais profissionais dos CEls na realização de reuniões e planejamentos - contribuindo para a integração PMI-CEI, receber suporte das coordenações dos CEls e do PMI, realizar leituras e pesquisas em prol do atendimento às demandas pedagógicas, entre outros.

De acordo com suas necessidades, professores do PMI relatam pesquisar em sua prática profissional por repertório musical (3), novas leituras (4), novos materiais (2), apreciação de shows, festivais e concertos (2). As finalidades são para aprender a lidar com pessoas (1), aprimorar o embasamento das práticas pedagógicas (1), sair da ignorância (1), como meio para superar as dificuldades (1) e atender aos projetos macro dos CEls (2):

Prof. Jorge - Por causa dessa provocação do espaço onde eu trabaIho [de ter que atender ao projeto pedagógico macro de um CEI], eu tive que arregaçar as mangas e procurar artistas daqui de Santa Catarina, pelo menos. Porque era para ser de Blumenau. Mas eu comecei a ficar angustiado, porque eu não estava achando aquilo [...]. Ou, as letras eram muito sensualizadas, ou, às vezes, o tipo de repertório. Eu não consegui tirar um proveito pedagógico daquilo. [...] $\mathrm{E}$, eu fui experimentando. Então, esse tipo de coisa, eu acho que faz a gente mudar. (Grupo Focal 02, 19/04/2018).

$\mathrm{O}$ atendimento aos projetos pedagógicos macro dos CEls - que envolvem todas as turmas da unidade - pelos professores de música é considerado como uma possibilidade no documento Projeto Musicalização Infantil - versão 2017. De acordo com o relato do Prof. Jorge, o atendimento às demandas específicas de cada CEI por meio da realização do projeto pedagógico macro - o exercício da prática profissional docente - proporciona aprendizagem profissional. Tal exercício se traduz na busca por novos repertórios visando o planejamento de atividades para as crianças em sintonia com o projeto pedagógico do $\mathrm{CEI}$, contribuindo para o desenvolvimento profissional docente. Sobre a prática profissional docente em música e o desenvolvimento de projetos escolares, Abreu (2015) afirma que:

A profissionalização docente em música no contexto escolar emerge não só das oportunidades abertas pelas escolas de educação básica, mas também do potencial do professor em atuar e desenvolver projetos na área. [...]. É praticando a profissão que o professor vai se tornando um profissional da docência em música. $O$ trabalho desses professores, na área de música, é validado não só pela formação em música, mas pelo coletivo que compõe o espaço escolar, sobretudo pelas respostas do aluno em sala de aula e nos projetos escolares (ABREU, 2015, p. 134).

Nesse sentido, o atendimento do professor de música aos projetos macro dos CEls e/ou no desenvolvimento de seus próprios projetos, a partir das respostas 
das crianças, colaboram para a profissionalização docente, visto que o professor se lança ao desconhecido para atender às demandas apresentadas no exercício da profissão. Sobre a aprendizagem profissional na prática, Gaulke (2017) compreende

[...] a atuação na escola como formação do professor, não como uma formação única nem como formação continuada, mas, sim, como aquilo que faz ele ser quem ele é na escola. A atuação constitui-se em experiência quando é avaliada, analisada, refletida. A experiência é a produção do saber da prática; assim, a experiência, como biografização, é condição para o saber-fazer. [...] Entender a atuação como formativa é uma tentativa de amalgamar formação e atuação, o que não significa que a formação inicial seja desnecessária, [...], nem que a atuação, em si, seja suficiente para que o professor se desenvolva profissionalmente. (GAULKE, 2017, p. 204-205)

Atuar na escola abrange tanto o desempenhar quanto o formar-se na profissão, inclusive pela atuação com outros profissionais, por meio do encontro com o outro. Em atuações conjuntas são possíveis as colaborações entre profissionais. No contexto do PMI, estas ocorrem entre professores do PMI e entre professores do projeto e professores de turma. No que diz respeito às oportunidades, desafios e necessidades sobre as colaborações, professores do PMI relataram que estar aberto ao outro (4) contribui para com o aprendizado profissional, bem como interagir, dialogar, compartilhar e trocar (8):

Prof. Jorge - Eu acho que as mudanças que eu tive, depende de mim aceitá-las ou descobri-las. Não é? Mas as pessoas com pelas quais eu passei me fizeram [...] possíveis essas mudanças. [...] essas pessoas [colegas de trabalho], se não tivessem sugerido essas leituras, eu não teria nem do que ter o arbítrio de ler aquilo ou não. Porque aquilo não existia para mim. [...]. Então, para mim, não depende só de mim [o desenvolvimento profissional docente]. Depende do outro também (Grupo Focal 02, 19/04/2018).

Pereira (2016, p. 65), por sua vez, reforça que professores de música reconstroem suas experiências anteriores através da interação e convivência com crianças e com outros profissionais que trabalham na educação infantil, e, conforme se apropriam do contexto, vão modificando sua forma de pensar, em direção a tornarem-se, além de professores de música, professores de crianças.

Professores do projeto afirmam que podem contribuir para o desenvolvimento profissional dos professores de turma (1) em relação à área musical. Numa via de sentido oposto, demonstram interesse em observar professores de turma atuando (3), pois aprendem sobre áreas além da música. A parceria (1) entre professores de música e professores de turma é considerada como oportunidade de aprendizagem, tanto que professores de música necessitam ter mais tempo para realizar o planejamento pedagógico com professores de turma (1). Outras formas de aprendizado ocorrem por meio de vivências e/ou partilhas com professores de turma (10): 
Profa. Glória - [...] são pequenos detalhes [...] que elas [professoras de turma] foram passando [...] [Eu] sempre trabalhava assim. Aí elas falavam "contextualiza o bicho que tu vais trazer". [...] Aí, eu comecei a contextualizar. Eu trazia foto do tatu quando contava a história do tatu. O que que é o tatu? Onde o tatu mora? Onde ele vive? Como é que ele é? Perguntar antes "o que é que é o tatu?" [...]. E foram essas coisas que elas me ensinaram. Que eu chegava e queria trabalhar direto o foco para música [do tatu]. Então, eu acho que a troca no espaço escolar, no espaço de trabalho, foram as experiências mais ricas no meu desenvolvimento profissional (Grupo Focal 02, 19/04/2018).

O encontro entre profissionais pode promover a partilha de conhecimentos, os professores de turma contribuem para a aprendizagem dos professores do PMI no que diz respeito aos conhecimentos do ensino e dos alunos, indo ao encontro das necessidades dos professores do PMI em relação a esses conhecimentos. Entretanto, professores de música relatam que há também desafios em relação à atuação com professores de turma. Afirmam que há problemas de atuação conjunta (6).

Profa. Bárbara - É que tem muitas salas ainda que as professoras estavam correndo da minha sala [aula] [professoras de turma que saiam da sala nos momentos de musicalização infantil]. E eu falei para a coordenadora [do $\mathrm{CEI}$ ] que as professoras não estão participando (Grupo Focal 01, 26/10/2017).

Essa situação é comumente relatada pelos demais professores do projeto. Ainda que a maioria dos professores de turma atue de forma colaborativa com professores de música, tentou-se superar tal questão por meio da elaboração da versão 2017 do PMI, pois nela está prevista a presença obrigatória dos professores de turma nos momentos de musicalização (BLUMENAU, 2017, p. 4).

Ao encontro das afirmações de Gaulke (2017) sobre a relação com os sujeitos escolares, foi a alteridade, o encontro/confronto com o outro, um dos fatores que levou à atualização do projeto - que visa o conforto com esse outro. Entretanto, apenas constar na versão 2017 do documento que a presença do professor de turma é obrigatória não é suficiente. Por isso fez-se necessária a socialização do documento, para os professores do PMI esclarecerem aos professores de turma que a presença deles é obrigatória porque a presença deles é importante e faz diferença no cuidar e educar da criança nos momentos de musicalização, pois são referência pedagógica da criança. Além do mais, são os professores de turma que conhecem com maior profundidade as crianças no tocante às suas restrições, limitações, características de aprendizagem e até, não menos importante, do histórico de acontecimentos da semana, tais como febres, acidentes, questões familiares, conflitos entre crianças, entre outros.

Em reuniões de trabalho do PMl após as socializações da versão 2017 do projeto em alguns CEls, professores de música relataram casos isolados de alguns professores de turma que manifestaram certa resistência quanto à obrigatoriedade de sua presença em sala de aula. Entretanto, há alguns anos que essa questão vem 
sendo discutida dentro da Educação Infantil do município. A presença dos professores de turma já vinha sendo solicitada como obrigatória. Isso já era um padrão procedimental, mas ainda não formalizado em documento oficial. Por isso buscouse a formalização de tal questão, visando a adequação desses casos isolados. De modo geral, os professores de turma atuam de forma colaborativa com os professores de música.

Professores de música revelam que foi no PMI a primeira vez que observaram outro professor de música atuar na educação infantil (2) e que o professor experiente precisar ser exemplo para os iniciantes (1). Houve relatos de dificuldades em anos passados sobre a não possibilidade de observar colegas professores de música no PMI (3) e de que em escolas particulares onde alguns professores trabaIharam também não era possível esse tipo de observação (3).

A partir de estudos que compõem sua revisão, Conway e Edgar (2014) relataram que professores iniciantes frequentemente sentem-se isolados de outros professores de música e de outros professores (KRUEGER, 1999 apud CONWAY; EDGAR, 2014, p. 485). A observação entre professores de música e as reuniões de trabalho contribuem para, além de outras questões, os professores iniciantes se integrarem ao PMI e se aproximarem dos colegas professores de música.

Em relação ao aprendizado entre professores de música, professores experientes relatam aprender quando recebem professores iniciantes para observá-los (2). O mesmo ocorre em relação aos professores iniciantes quando observam e/ou interagem com professores experientes (17). Colaborações entre pares e/ou com o grupo (10) também geram aprendizado. Especificaram apenas a ampliação de repertório (1) e o como lidar com a criança (1) como conhecimentos aprendidos com os colegas da mesma área. Exemplo de professora quando iniciou na profissão e de professor experiente recebendo iniciantes:

Profa. Rafaela - Eu peguei uma fase boa. 2015 foi uma fase boa, porque eu consegui assistir às essas aulas [assistiu a três professores do PMl], que eu consegui dar essa alavancada no começo.

[...]

Prof. Jorge $-[\ldots]$ isso eu aceito com muito prazer [ser observado por professores iniciantes]. Sempre. [...] eu vejo como é importante para mim. Por isso que aquela vez que a Profa. Maitê [iniciante] veio comigo [acompanhá-lo] eu me esforcei ao máximo. Para fazer o mais [...] por ela possível, assim. Para que ela não desista por falta de estímulo, [...] de referências (Grupo Focal 01, 26/10/2018).

Nota-se uma via de mão dupla de aprendizagem no encontro entre professores iniciantes e experientes. Nesse sentido, McDiarmid (1995) afirma que professores necessitam "pertencer a uma comunidade de colegas que influencie fortemente suas tentativas de repensar ou mudar suas práticas ou mesmo de aprender novas práticas" (MCDIARMID, 1995 apud MIZUKAMI et al, 2010, p. 79-80). Essa comunidade, conforme explica o autor, precisa ser suficientemente flexível para acomodar professores de diferentes repertórios e níveis de aprendizagem.

Conway (2001), reforçando a importância do "agir em comunidade", ende- 
reça algumas sugestões para programas de formação de professores de música, entre elas "[...] a observação de professores de música experientes e a recepção de observações de especialistas em conteúdo musical, [...] além do envolvimento com organizações musicais de ensino superior e de nível nacional" (CONWAY, 2001 apud CONWAY; EDGAR, 2014, p. 486).

\section{Conclusão}

Considera-se que os professores do Projeto Musicalização Infantil se desenvolvem profissionalmente nos encontros e interações entre si, com professores de turma e com as crianças. Nas interações entre professores de música há um reconhecer-se na categoria profissional e um apoio mútuo com vistas para a aprendizagem e novas conquistas, desde inserções de professores de música iniciantes a reivindicações em prol da inclusão de professores do PMI na comunidade profissional do município.

Nas interações com professores de turma, professores do PMI aprendem sobre a criança - conhecimento do aluno, o que colabora para desenvolverem suas práticas de musicalização - conhecimento do ensino. E, é no atendimento da e com a criança, na atuação, que os professores fazem e aprendem a profissão. Os desafios presentes nesses encontros - interações, quando possíveis de se transpor, também geram mudanças e, por conseguinte, o desenvolvimento profissional.

\section{Referências}

ABREU, Delmary Vasconcelos de. Narrativas de profissionalização docente em música: uma epistemologia política na perspectiva da Teoria Ator-Rede. Revista da ABEM, v. 23, n. 34, p. 125-137, Londrina, 2015. Disponível em <http://www.abemeducacaomusical.com.br/revistas/revistaabem/index.php/revistaabem/article/view/527/439 > . Acesso: 23 de ago. de 2018.

BLUMENAU. Prefeitura Municipal de Blumenau. Poder Executivo. Decreto № 9645/2012. Regulamenta a implantação da hora-atividade extraclasse no âmbito do magistério público municipal de Blumenau. Blumenau, 2012. Disponível em: <https://leismunicipais.com.br/pdf/Decreto-9645-2012-Blumenau-SC.pdf>. Acessado em 06/abril de 2017.

BLUMENAU. Secretaria Municipal de Educação. Projeto Musicalização Infantil. Versão 2017. Blumenau, 2017.

BRASIL. Parecer CNE/CEB no 18/2012. Reexamina o Parecer CNE/CEB no 9/2012. Parecer Homologado. Ministério da Educação. Conselho Nacional de Educação. Câmara de Educação Básica. Brasília, 2012. Disponível em <http://portal.mec.gov.br/index.php?option=com_docman\&view=download\&alias =11795-pceb018-12\&ltemid=30192> . Acesso: 20 jul. 2018.

CONWAY, Colleen M.; EDGAR, Scott N.. Inservice Music Teacher Professional Development. In: CONWAY, Colleen M. (Ed.). The Oxford handbook of qualitative research in American music education. Oxford Handbooks Online. Oxford University Press, 2014. Disponível em <http://www.oxfordhandbooks.com/view/10.1093/oxfordhb/9780199844272.001.0001/oxfordhb-9780199844272-e-025 > . Acesso: 21 nov. 2017.

GAULKE, Tamar Genz. Aprendizagem da docência: um estudo com professores de música da educação 
básica. Revista da ABEM, v. 21, n. 31, p. 91-104, Londrina, 2013. Disponível em <http://www.abemeducacaomusical.com.br/revistas/revistaabem/index.php/revistaabem/article/view/645/474>. Acesso: 4 de ago. de 2018.

GAULKE, Tamar Genz. O desenvolvimento profissional de professores de música da educação básica: um estudo a partir de narrativas autobiográficas. 2017. 228 f. Tese (Doutorado) - Curso de Doutorado em Música, Programa de Pós-graduação em Música, Universidade Federal do Rio Grande do Sul, Porto Alegre, 2017. Disponível em <http://www.lume.ufrgs.br/handle/10183/165447> . Acesso: 24 nov. 2017

HOOKEY, Mary Ross. Professional Development. In: COLWELL, Richard; RICHARDSON, Carol (Ed.). The new handbook of research on music teaching and learning: A Project of the Music Educators National Conference. New York: Oxford University Press, 2002.

MIZUKAMI, Maria da Graça N. et al. Escola e aprendizagem da docência: processos de investigação e formação. São Carlos: EdUFSCar, 2010.

MIZUKAMI, Maria da Graça N.. Escola e desenvolvimento profissional da docência. In: GATTI, Bernardete A. et al. Por uma política nacional de formação de professores. São Paulo: UNESP, 2013, p. 23-54.

PEREIRA, Joana Lopes. Trajetórias de trabalho na educação infantil: um estudo com professores(as) de música da Rede Municipal de Ensino de Porto Alegre-RS. Revista da ABEM, v. 24, n. 37, p. 53-66, Londrina, 2016. Disponível em <http://www.abemeducacaomusical.com.br/revistas/revistaabem/index.php/revistaabem/article/view/645/474 > . Acesso: 4 de ago. de 2018.

SANDÍN ESTEBAN, Maria Paz. Pesquisa qualitativa em educação: fundamentos e tradições. Porto Alegre: Artmed, 2010.

YIN, Robert K. Estudo de caso: planejamento e métodos. 4. ed. Porto Alegre: Bookman, 2009.

Recebido em 24/09/2018 - Aprovado em 23/10/2018

Como citar:

OLIVEIRA, Gian Marco de; SCHAMBECK, Regina Finck. Desenvolvimento profissional docente: um estudo de caso com professores do Projeto Musicalização Infantil de Blumenau/SC. ouvirOUver; Uberlândia, v.14,n.2, p, 452-465, jul./dez. 2018. Disponível em: http://www.seer.ufu.br/index.php/ouvirouver; DOI:http://doi.org/10.14393/OUV23-v14n2a2018-14 